\title{
CONCRETIZAÇÃO AO NÍVEL MUNICIPAL DOS PMDFCI
}

\author{
Duarte Gomes Marques
}

Apresentação integrada no painel sobre a Visão e Execução. Esta apresentação pretende refletir a experiência pessoal e profissional da concretização ao nível Municipal dos PMDFCI, assim como "aprendizagens" obtidas com o decorrer da preparação e elaboração dos PMDFCI, nas suas várias "geraçóes" de elaboração/aplicação e o esforço promovido, enquanto técnico florestal, para a sua respetiva implementação para o alcance dos seus objetivos de proteção da floresta e segurança das pessoas e bens.

Desde a implementação deste instrumento de gestão, o PMDFCI tem vindo a aumentar a sua abrangência e complexidade. Numa primeira fase, a que apelidamos de 1. a geração os PMDFCI foram, essencialmente, para resolução das obrigaçóes legais. Tendo significativas debilidades no que toca à eficácia efetiva para a defesa da floresta face aos incêndios. Os Planos caraterizam-se por serem muito densos em informação de contexto e generalistas, constatando-se uma falta de eficácia e articulação da estratégia de Defesa de Floresta Contra Incêndios (DFCI). Motivada por debilidades do dimensionamento dos meios e recursos afetos à sua implementação, ao frágil contributo da maioria das entidades e serviços envolvidos na sua elaboração. Trabalho de elaboração que recaia essencialmente na autarquia e, dentro desta, no técnico do Gabinete Técnico Florestal, levando, na maioria das vezes, a uma insuficiente coordenação, execução, monitorização e avaliação dos planos municipais pelas entidades envolvidas. Os PMDFCI, nesta fase, apresentavam, na sua 
globalidade, um diagnóstico pouco sólido, elaborado com informação de base pouco atual e sem rigor no apuramento das necessidades de intervenção, e plano de ação pouco coerente e exequível.

Nos PMDFCI, ditos, de 2. a geração, aqueles que na globalidade dos Municípios se encontram atualmente em vigor sofreram uma melhoria assinalável comparativamente aos anteriores. Para além da preocupação das obrigações legais, evoluíram nas preocupaçóes com reforço da eficácia da floresta contra incêndios, nomeadamente da definiçâo de açôes e na sua localização com a gestão de combustíveis. Contudo, as suas principais preocupaçóes centraram-se na "limpeza de combustíveis"; "corte de árvores"; "educação/sensibilização da população"; "proibição/ condicionamento do uso do fogo"; "reforço da fiscalização — levantamento de autos"; entre outras de carácter muito restrito e segmentado, muito numa perspetiva de quantificação de açôes/operaçóes "estandardizadas" sem, muitas vezes, atender a diversidade do espaço florestal (e rural) e às especificidades, dinâmicas e funcionalidades destes espaços e dos seus intervenientes.

$\mathrm{Na} 3 .^{a}$ geração dos planos, que se encontra na fase inicial, os PMDFCI ou instrumentos "equivalentes" ("programas") a produzir, na nossa conceção, além, naturalmente, de garantir as obrigaçóes mais formais e regulamentares, devem garantir e promover uma proatividade e complementaridade de atuação superior dos intervenientes e níveis (local/municipal, intermunicipal, regional e nacional) na gestáo e ordenamento do território, numa visão integral de gestáo do espaço rural/territorial. Os PMDFCI não devem ser a (única) estratégia para a proteção/gestão de um território, mas, isso sim, fazer parte da estratégia de melhoria de gestão e valorização do território. Para isso, entendemos que é necessário alocar a estes processos de conceção e implementação mais recursos (financeiros e outros) e uma maior cooperaçáo na gestáo do território, com um maior foco na dimensáo local, aproveitando quem está no território e ainda capaz/disponível para o fazer e deste modo colaborar ativamente nessa, entendemos nós, imprescindível e insubstituível missão.

Nesta visão, que entendemos ser a mais adequada para a concretizaçáo eficaz ao nível Municipal dos PMDFCI, apresentamos de seguida dois casos práticos que se pretendem ser mais elucidativos da abordagem acima descrita e possam contribuir para a mobilização e capacitação de todos nós neste grande desafio que é a gestão dos incêndios florestais. 
O modelo de gestão e valorização do pastoreio na gestão florestal — "Terra Maronesa" e modelo de gestáo e valorizaçáo integrada do pinhal estão a ser implementados no concelho de Vila Pouca de Aguiar e apresentam-se aqui como exemplos, ainda que com fraquezas e oportunidades, para aquilo que entendemos, numa visão mais integrada e holística, que deve ser a gestão do espaço rural/territorial com enfase na gestão e ordenamento do território.

\section{MODELO DE GESTÃO E VALORIZAÇÃO DO PASTO- REIO NA GESTÁO FLORESTAL/TERRA MARONESA}

Ao invés dos grandes sistemas montanhosos europeus, as montanhas portuguesas têm uma altitude pouco elevada e uma fisiografia dominada por superfícies planálticas, onde os grandes declives são escarpas de falha ou resultam do encaixe de linhas de água. As áreas de montanha acima dos $700 \mathrm{~m}$ de altitude ocupam cerca de 11\% (10 $\left.000 \mathrm{~km}^{2}\right)$ da superfície de Portugal Continental, concentradas no Norte e Centro do país (40\%) (Aguiar et. al. 2009). Apenas 0,5\% do território nacional tem altitudes superiores a $1100 \mathrm{~m}$.

Nas regióes Norte e Centro de Portugal Continental evidenciam-se quatro grandes alinhamentos montanhosos acima dos $700 \mathrm{~m}$ :

- Montanhas Galaico-portuguesas que se iniciam na Serra da Peneda e até à Serra da Aboboreira, que estabelecem a primeira linha de montanhas frente ao mar;

- Serras Galaico-durienses que abrangem os sistemas montanhosos de Trás-os-Montes;

- Serras Beira-durienses que incluem as serras de Montemuro, Freita, Leomil, Lapa e Penedono;

- Sistema Central que abarca as serras da Malcata, Estrela, Gardunha, Açor e Lousã.

O projeto Terra Maronesa está dirigido às áreas de montanha do noroeste de Portugal, mais concretamente às montanhas Galaico-portuguesas. Dada a proximidade do mar, este alinhamento montanhoso tem um clima temperado ou temperado-submediterrânico, i.e., um clima húmido com período de deficit de água no solo curto, de 1-2 meses. Estas condições ecológicas estão correlacionadas com a presença do Ulex minor (tojo-molar) e de clareiras com vegetação herbácea vivaz. 
O tojo-molar através das bactérias diazotróficas simbiontes alojadas na raiz, tem a capacidade de fixar azoto atmosférico. Consequentemente, a sua biomassa é rica em proteína bruta (ca. 10\%) e desejada pelos herbívoros domésticos. Foi provado que na montanha, somente os baldios com tojo-molar têm um coberto vegetal adequado ao pastoreio por bovinos. Por essa razão também, em todas as grandes montanhas com tojo-molar se diferenciou uma raça bovina autóctone (e.g. cachena, barrosã, maronesa e arouquesa) (Aguiar et al 2009).

Este projeto assenta no sistema de maneio e gestão do território tem vindo a ser desenvolvido na serra do Alvão por alguns criadores (poucos para já), recriando, com significativas alteraçóes, um sistema agropastoril cuja memória se desvanecia. Por alguma razão a raça bovina maronesa era no passado conhecida como vaca serrana.

As principais características deste novo sistema são as seguintes:

- As vacas são mantidas todo o ano na montanha, deslocando-se serra acima e serra abaixo, em plena liberdade, consoante as condiçôes meteorológicas;

- Os alimentos para os animais são todos produzidos no interior do sistema; nos períodos mais quentes ou frios o pasto é suplementado com o feno produzido nos lameiros a baixa altitude;

- O bem-estar animal é maximizado porque o contacto humano é minimizado, não há restriçóes ao movimento e à escolha de pasto, as pariçóes e a amamentação ocorrem sem a intervenção dos criadores, e os animais podem expressar livremente comportamentos inatos (e.g. hierarquização social e organização em haréns);

- A saúde dos efetivos (e.g. vacinação) e a extração de animais faz-se com mangas desenhadas para diminuir o stress animal;

- As despesas com a saúde animal resumem-se ao cumprimento dos calendários de vacinação e desparasitaçáo;

- Os animais recém-nascidos doentes (e inviáveis) são eliminados (com redução dos custos) pelo lobo;

- As vacas criadas na montanha, além de mais saudáveis, desenvolvem comportamentos defensivos complexos contra o lobo (e.g. creches e círculos defensivos); os estragos causados pelo lobo nas manadas bem manejadas são praticamente nulos;

- A eficiência do trabalho cresce significativamente (um único criador pode gerir uma manada de 100), os custos diminuem, e as margens brutas por animal aumentam. 
Como referido, estão já em curso algumas experiências práticas deste sistema, nomeadamente nos baldios da Serra do Alvão, e os efeitos ecológicos da reintrodução da vaca são notáveis:

- A herbivoria diminui assinalavelmente as taxas de crescimento da vegetação arbustiva e a acumulação de combustíveis lenhosos; os fogos são hoje muito menos intensos e os povoados e caminhos públicos que lhe dão acesso, estão melhor defendidos do fogo;

- A herbivoria acelerou o turnover dos nutrientes no sistema e, por essa via, incrementou a produtividade primária (fixando as condiçóes ambientais, a produtividade primária depende sobretudo da pool de nutrientes e do seu turnover);

- O uso de fogo controlado complementa o efeito dos herbívoros no sistema; o fogo foi domesticado e transformado num valioso instrumento de gestão;

- A acentuada reduçáo da intensidade/severidade do fogo salvaguarda o stock de carbono na matéria orgânica do solo, e permite a sua recuperação nas áreas recentemente afetadas por grandes fogos rurais;

- O grau de cobertura da vegetação herbácea de maior valor alimentar para os animais aumentou;

- Mais erva significa mais presas para o lobo e densidades acrescidas desta espécie chave;

- Havendo mais gado na serra é preciso produzir mais feno nas terras baixas para consumir durante os períodos de escassez de pasto, consequentemente, terras abandonadas, cobertas de matos, estão a ser convertidas em lameiros e a fertilidade dos seus solos corrigida com a aplicaçáo de calcários;

- Os lameiros de fenos são um habitat Rede Natura, com uma relevância cultural e biológica objeto de uma aturada investigação por toda a Europa;

- Há mais gente e vigilância na montanha, e a montanha voltou a produzir riqueza, tanto sob a forma de bens privados e como de bens públicos, com e sem valor mercantil.

Assim, a reintrodução da pastorícia com vacas na Serra do Alvão compatibiliza interesses privados (e.g. venda de animais) com interesses coletivos (e.g. reduçáo da intensidade e dos acidentes com fogos, aumento da retençáo da água e da fertilidade do solo, paisagem e a conservação do lobo). 
Atualmente o projeto foca-se no território da serra do Alvão, mas assume-se como "projeto piloto" passível de replicação noutros territórios de montanha temperada e temperada submediterrânica em Portugal, e não só. Este imenso território (à escala nacional) abrange vários concelhos economicamente deprimidos, num processo acentuada desertificação humana (e.g., Baião, Montalegre, Ribeira de Pena, Terras de Bouro, Mondim de Basto e Vila Pouca de Aguiar). Embora primariamente dirigido aos produtores de gado, pretende-se que venha a ter um efeito multiplicador em outras atividades económicas regionais (e.g. turismo, restauração, comércio de produtos agrícolas, empresas de aluguer de máquinas, empresas de materiais de construção, setor da construção civil).

O Projeto: "Terra Maronesa" é um projeto integrado e participativo que pretende valorizar a raça autóctone Maronesa nas suas diferentes vertentes: cultural; social/económica; ambiental e turística (http:// terramaronesa.pt/).

\section{MODELO DE GESTÁO E VALORIZAÇÃO INTEGRADA DO PINHAL}

A ausência de gestáo e de valorização dos povoamentos de pinheiro bravo está na origem da sua forte degradação e desaparecimento, sobretudo por ação dos incêndios florestais (redução de 263 mil ha entre 1995 e 2010, ICNF, IFN6).

No caso da gestão das áreas comunitárias (baldios), nomeadamente as submetidas ao regime florestal na modalidade de cogestão com o ICNF, estas foram sofrendo ao longo dos últimos anos — de forma mais acentuada desde a década de 80 do séc. XX — importantes alteraçóes que tiveram reflexos importantes na gestão, valorização e proteção dessas áreas. Em resultado, verificou-se uma diminuição da capacidade de gestão e consequente subaproveitamento ou destruição de recursos, em particular por açáo do fogo. Face a esta realidade, tem-se vindo desde há alguns anos a equacionar - no âmbito das próprias estruturas da tutela e do setor florestal/rural em geral - a necessidade de desenvolver e implementar novas formas de gestão, de proteção, de valorização, de utilização e de supervisão destes territórios, mais adequados às atuais funçóes e capacidades do estado, às realidades e necessidades locais, e às novas funçóes a desempenhar por estes territórios. 
O modelo de gestáo e valorização integrada do pinhal, atualmente implementado em Vila Pouca de Aguiar, pretende contribuir de forma importante para a obtenção de resultados e de alternativas de gestáo que se afigurem como soluçóes integradas, racionais e sustentáveis, procurando alcançar os seguintes objetivos:

- Implementaçáo de soluçóes de gestão inovadoras no ecossistema pinhal bravo, através da complementaridade entre atividades, funções e entidades;

- Valorizar os pinhais e implementar gestão ativa sustentável através da exploração racional de recursos lenhosos e náo lenhosos, com base na exploração de resina;

- Diminuição da incidência e do impacto dos incêndios florestais;

- Eliminar a sazonalidade e intermitência do emprego na resinagem, tornando-os progressivamente em operacionais florestais a tempo inteiro, agentes de proteçáo e desenvolvimento na sua área de residência;

- Sustentabilidade económica da contrataçáo permanente de ativos na resinagem através da afetação de atividades de silvicultura, de DFCI e da exploração de outros produtos florestais não lenhosos (PFNL);

- Avaliar o contributo destes ativos florestais - munidos com os devidos equipamentos, formação e coordenação e integração adequadas- para a realização de açóes de prevenção estrutural e de apoio à deteção, primeira intervenção e vigilância de rescaldos a incêndios florestais, com integração no dispositivo municipal de DFCI;

- Aumento da produção de resina, importante matéria-prima para a indústria nacional, diminuindo as importaçóes e a dependência externa.

Este modelo está a ser implementado na freguesia de Tresminas numa extensa área florestal, aproximadamente 500 ha, ocupada com povoamentos de pinheiro bravo com características que permitem a sua orientação para a produção de resina e para a colheita e valorização de outros produtos florestais náo lenhosos, nomeadamente de cogumelos silvestres, espargos e de pinhas. A floresta é a principal ocupação deste território de montanha e constitui o seu maior potencial de desenvolvimento. 
Com o aproveitamento dos recursos não lenhosos, nomeadamente a resina, que se apresenta como uma matéria-prima natural e renovável, utilizada como alternativa dos derivados do petróleo. Consegue-se, por um lado, o aproveitamento e valorização desta matéria, com grande procura no mercado europeu e mundial e por outro, contribuir para a diversificação das atividades económicas em zonas rurais desfavorecidas. Seja na criaçáo de emprego estável e no incremento da gestão florestal, com consequências no aumento da resiliência aos incêndios rurais e na diminuição da importação de matéria-prima para a indústria nacional. A atividade resineira assume um papel primordial na valorização do pinhal e no aumento da rentabilidade do proprietário florestal.

A organização e gestão da atividade de resinagem com um número de trabalhadores significativos (10 elementos) representa uma dimensão adequada, por questóes logísticas e de organização de trabalho. Cada resineiro tem capacidade para a ser responsável por de cerca de 8000 bicas de resina. A exploração de resina permite, através da sua extração e venda, a sustentabilidade da contrataçáo desses 10 resineiros durante um período de cerca de 8 meses, sendo que, é expectável que com a melhoria deste modelo permita, futuramente, rentabilizar a máo-de-obra para outras atividades importantes (apanha de cogumelos, pinhas, trabalhos de defesa da floresta contra incêndios) permitindo assim a manutenção dos postos de trabalho a tempo inteiro.

A gestáo operacional deste modelo tem por base equipas operacionais de trabalhadores florestais com capacidade e impacto na gestáo florestal e na defesa da floresta, sobretudo no apoio ao combate a incêndios florestais.

A resinagem, ao coincidir com o período de maior risco de incêndio (abril a novembro), permite que os resineiros, com meios, formação, organizaçáo e enquadramento, e através da sua presença intensa e elevado conhecimento das áreas, colaborem ativamente na vigilância, deteçáo e primeira intervenção no combate a incêndios florestais, o que não acontece em muitas das áreas florestais do nosso país.

A implementação e melhoria deste modelo vai permitir uma maior atratividade por parte dos proprietários e gestores de áreas de pinhal. Assim, através da valorização de produtos florestais náo lenhosos, em particular da resina, os proprietários podem perspetivar uma antecipação de ganhos intermédios ao longo dos anos, não tendo assim de esperar pelo abate final da árvore para obter rendimento. Este fator é 
determinante, uma vez o abandono da floresta se verifica pela sua falta de rentabilidade, conduzindo à acumulação de combustíveis (essencialmente matos) ao longo dos anos, agravando o risco de incêndio e respetiva perda dos seus bens em caso de incêndios. 